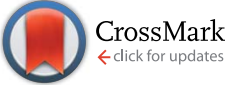

Cite this: RSC Adv., 2017, 7, 14981

Received 19th December 2016 Accepted 23rd February 2017

DOI: 10.1039/c6ra28407h

rsc.li/rsc-advances

\section{Corrosion behavior of Al film on uranium in salt spray test}

\author{
Yanping Wu, ${ }^{*}$ Shengfa Zhu, ${ }^{*}$ Peng Shi, Biaojie Yan, Dingzhou Cai and Yuping Zhang \\ The corrosion behavior of Al film coated uranium and bare uranium under neutral salt spray conditions are \\ evaluated. Moreover, the corrosion process and electrochemical mechanism are investigated. Pits in \\ uranium appear in the initial stage of the salt spray test, which link to each other to form a ring-like \\ morphology along the machining trace. The corrosion product on the surface of uranium is a mixture of \\ $\mathrm{U}_{3} \mathrm{O}_{8}$ and $\mathrm{UO}_{2}$. After salt spray for $1.5 \mathrm{~h}$ and sealed reservation for 1 month, some corrosion particles \\ spalled off from the Al film. The Al film is eroded first as the sacrificial anode upon exposure to salt spray, \\ which exhibits its excellent protection effect for uranium.
}

\section{Introduction}

Uranium is widely applied in the nuclear energy field, medical science, breeding, etc. ${ }^{1,2}$ Depleted uranium is a nuclear waste in the uranium enrichment process, and hence the ${ }^{235} \mathrm{U}$ content of depleted uranium is about $0.2-0.4 \%$ less than that of natural uranium. Therefore, it is less radioactive and usually used as depleted uranium ammunition and depleted uranium-armored tanks. However, depleted uranium is prone to corrosion in the environment due to its high chemical reactivity. The corrosion products of uranium present environmental and health hazards. ${ }^{3-5}$ Surface coatings have been used to improve its corrosion performance. Protective coatings, such as zinc coatings, ${ }^{6}$ Al-based coatings, ${ }^{7-9}$ Ti-based coatings ${ }^{8,10}$ and Cr-based coatings, ${ }^{11,12}$ have been prepared to enhance the corrosion resistance of uranium.

Several methods have been used to investigate the corrosion resistance of uranium and its alloys. Research was conducted by observing changes in the atmosphere and the weight gain of samples. ${ }^{13-15}$ Electrochemical techniques were considered to be common and effective methods to evaluate the corrosion behavior of uranium and alloys. ${ }^{16-26}$ When exposed to an ocean atmosphere in service, active anions, such as $\mathrm{Cl}^{-}$, invade the matrix to corrode uranium. Salt fog causes high corrosion of materials. The porosity of films affects the corrosion resistance by providing preferential paths for the corrosive species, which causes galvanic corrosion at the interface between the film and substrate..$^{27,28}$ Kochen et al. ${ }^{29,30}$ reported the corrosion potential and corrosion rate of uranium alloys in simulated sea water. Bland $e t a l .{ }^{31}$ reported the corrosion property of ion plated $\mathrm{Cu}$, $\mathrm{Au}, \mathrm{Cr}$ and $\mathrm{Al}$ films on uranium, which showed that the ion

Institute of Materials, China Academy of Engineering Physics, Jiangyou 621907, Sichuan, PR China.E-mail: wuyanping-2@126.com; zhushengfa@caep.cn; Fax: +86816-3626744; +86-816-3626746; Tel: +86-816-3626744; +86-816-3626746 plated Al film had the best corrosion resistance. The galvanic corrosion between depleted uranium and steel was also studied. The Volta potential was evaluated by scanning a Kelvin probe. ${ }^{32,33}$ There have been few investigations on the corrosion products and corrosion morphology of uranium. Therefore, it is meaningful to study the corrosion behavior of Al film coated uranium and bare uranium in the salt fog environment. After the materials are removed from the salt fog environment, the corrosion pits expand due to the reactivity of the active anions in their surfaces. It is necessary to study the corrosion process of uranium and $\mathrm{Al}$ films deposited on uranium in the accelerating mode by salt spray tests to simulate ocean atmosphere corrosion.

In this study, an Al film on the surface of uranium (depleted uranium) was deposited via the magnetron sputtering technology. A neutral salt spray test was carried out to simulate the ocean atmospheric corrosion behavior of uranium and $\mathrm{Al}$ film on uranium. The samples were reserved in sealed chamber for 1 month after the salt spray test to evaluate the corrosion process. The morphology and chemical element compositions after the salt spray test were analyzed. The mechanism of salt spray corrosion is discussed to investigate the corrosion behavior of uranium (denoted as $\mathrm{U}$ for short) and $\mathrm{Al}$ film deposited on uranium (denoted as $\mathrm{Al} / \mathrm{U}$ for short) under the ocean atmosphere with electrochemical performance tests.

\section{Experimental}

\subsection{Al film preparation}

The sputtering of the Al film was carried out on a magnetron sputtering instrument. The target was sintered $\mathrm{Al}$ of $99.99 \%$ purity. $\Phi 25 \times 2 \mathrm{~mm}$ uranium samples were placed into a vacuum chamber after ultrasonic cleaning in acetone and alcohol. The distance between the substrate and the target was kept at $100 \mathrm{~mm}$. After the base pressure was pumped just below 
$5 \times 10^{-4} \mathrm{~Pa}$, the working pressure was kept at $0.3 \mathrm{~Pa}$ with argon (99.999\% purity) flowing into the chamber with a flow of 40 sccm to carry out the deposition process. The substrate temperature was kept at $473 \mathrm{~K}$ during the deposition. The target power was $3 \mathrm{~kW}$ during the sputtering process. The bias voltage was $-100 \mathrm{~V}$. The thickness of the $\mathrm{Al}$ film obtained was approximately $10 \mu \mathrm{m}$.

\subsection{Film characterization}

The structure of the film was measured using an Empyrean $\mathrm{X}$ ray diffractometer employing $\mathrm{Cu} \mathrm{K} \alpha$ radiation $(\lambda=0.15406$ $\mathrm{nm})$. The morphology of the sample before and after the salt spray test was observed by scanning electron microscopy (KYKYEM3200) and optical microscopy (OLS-4000). Energy dispersion $\mathrm{X}$-ray spectroscopy (EDX) was used to analyze the composition of the corrosion product.

\subsection{Salt spray corrosion test}

Neutral salt spray corrosion tests ${ }^{34}$ were performed according to ASTM B117-97. Tests on five samples were performed in a salt spray chamber and the experimental conditions were as follows: continuous salt spray of $5 \pm 0.5 \mathrm{wt} \% \mathrm{NaCl}$ (purity of 99.5\%) solution; temperature of $35{ }^{\circ} \mathrm{C} \pm 1{ }^{\circ} \mathrm{C}$; pH of $6.5-7.2$; and deposition rate of $1.5 \mathrm{~mL} / 80 \mathrm{~cm}^{2} \mathrm{~h}$, all within the specifications given in ASTM B117-97. The backsides and rims of the samples were sealed with epoxy resin. Samples were observed by optical microscopy every $0.5 \mathrm{~h}$. After the salt spray test, samples were reserved in a sealed chamber. The reservation conditions were as follows: temperature of $25{ }^{\circ} \mathrm{C}$ and humidity of $20 \% \mathrm{RH}$. The morphologies and chemical element compositions were analyzed after the salt spray test.

\subsection{Electrochemical corrosion tests}

Electrochemical tests were carried out using a PARSTAT 2263 electrochemical workstation equipped with three electrodes. The sample was set as the working electrode. A graphite electrode and saturated calomel electrode (SCE) were used as the counter and reference electrodes, respectively. The effective area of the samples was $1 \mathrm{~cm}^{2}$ embedded in epoxy resin. The experiments were performed in $50 \mu \mathrm{g} \mathrm{g}^{-1} \mathrm{Cl}^{-}$solution in distilled water. The chemical used in the experiment was $\mathrm{KCl}$ (AR, purity of $99.5 \%$ ). The samples were dipped in the solution to reach the steady open circuit potential (OCP). The potential sweep rate of $2 \mathrm{mV} \mathrm{s}^{-1}$ was adopted to perform the potentiodynamic polarization tests.

\subsection{Corrosion product analysis}

Raman spectra of depleted uranium after salt spray corrosion were recorded with an XploRA Raman spectrometer (Horiba Jobin Yvon Company). The spectra were accumulated with a resolution of $\sim 4 \mathrm{~cm}^{-1}$ and an excitation source of $532 \mathrm{~nm}$ radiation from an $\mathrm{Nd}$ : $\mathrm{YVO}_{4}$ laser (frequency-doubled).

The AES depth profile was used to analyze the distribution of $\mathrm{C}, \mathrm{O}, \mathrm{Al}$ and $\mathrm{Cl}$ elements for the $\mathrm{Al}$ film after the salt spray test. The AES instrument model was PHI650 SAM, the excitation energy was $3 \mathrm{keV}$, electron beam current was $100 \mathrm{nA}$, and sputtering area was $1 \mathrm{~mm}^{2}$.

\section{Results and discussion}

\subsection{Al film characterization}

The surface and cross-section morphologies of the Al film prepared via magnetron sputtering are shown in Fig. 1. From the SEM images, it can be seen that the micro-structure of the $\mathrm{Al}$ film is densely packed, with no voids and no micro-cracks (Fig. 1a). A few macro-particles are found on the surface. The maximum size of the particles is about $0.5 \mu \mathrm{m}$. Fig. $1 \mathrm{~b}$ shows the cross-section image of the Al film. There was no columnar crystal structure in the film. The thickness of the Al film was about $10 \mu \mathrm{m}$.

To evaluate the phase structure of the Al film, XRD analysis was performed. Fig. 2 shows the XRD patterns of the Al film. The coexistence of (111), (200), (220), (311) and (222) peaks reveal that $\mathrm{Al}$ has no distinct preferential orientation. It can be observed that the peaks are relative to the data of the standard PDF 04-0787.

\subsection{Results of salt spray corrosion}

Fig. 3 illustrates the macro-optical morphologies of $\mathrm{U}$ and $\mathrm{Al} / \mathrm{U}$ after $1.5 \mathrm{~h}$ salt spray corrosion. Two typical features are observed for uranium: small pits (Fig. 3a) and large corrosion zones (Fig. 3b). A few corrosion pits appear in the uranium surface after $0.5 \mathrm{~h}$ exposure in the salt spray. As the corrosion time increased, the number of pits increased, the diameter of pits expanded gradually, and the pits began to connect with each other. The small pits are almost exhibited in the machining trace. The large corrosion zones are due to the connecting of small corrosion pits. The largest depth of the corrosion area is about $18.04 \mu \mathrm{m}$. There is no significant change in the $\mathrm{Al}$ film after the $1.5 \mathrm{~h}$ salt spray test, as shown in Fig. 3c and $\mathrm{d}$.

Fig. 4 shows the micro-structure and EDX result of the Al film and uranium after $1.5 \mathrm{~h}$ salt spray corrosion. Fig. 4a is the SEM image of uranium after the salt spray corrosion test. From the EDX patterns of spots 1-3, it can be observed that the elements ( $\mathrm{U}, \mathrm{C}$ and $\mathrm{O}$ ) in the corrosion area (spot 1 and spot 2) are identical with the matrix (spot 3 ). In contrast, Fe or Al elements have strong lines in the corrosion area (spot 1 and spot 2). The impurity elements could lead to surface heterogeneity and
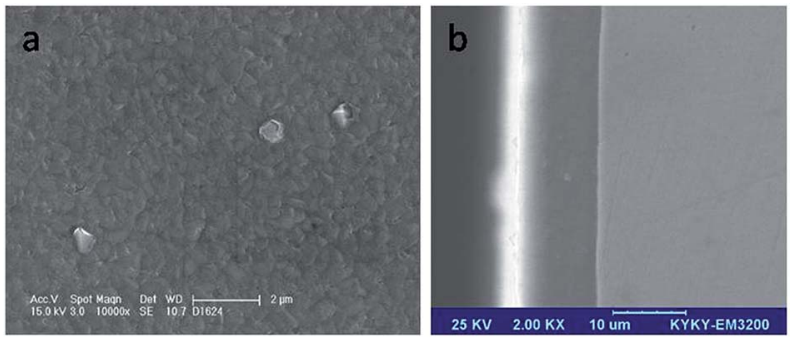

Fig. 1 Surface image (a) and cross-section image (b) of the Al film. 


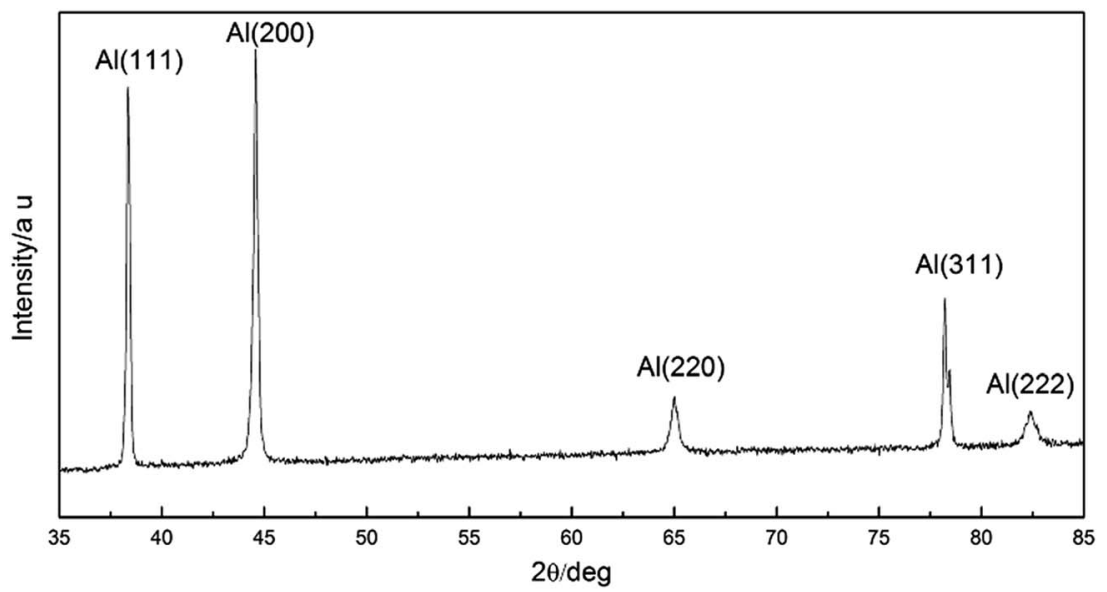

Fig. 2 XRD spectrum of the Al film.

induce corrosion features. ${ }^{3}$ These impurity elements influence the corrosion morphology and increase the corrosion rate, which is irrelevant to the corrosion nucleation site. Cracks were found on the surface of uranium, which caused spalling phenomena, as shown in Fig. 4b. The Al film was only slightly corroded with a dense layer of corrosion products on the top of the film after $1.5 \mathrm{~h}$ salt spray corrosion, as shown in Fig. $4 \mathrm{c}$. The EDX result of the Al film after salt spray corrosion is shown in Fig. 4c (spot 4), in which $\mathrm{Al}$ and $\mathrm{O}$ atoms are the main compositions of the film, which indicates that the base uranium was well protected.

Fig. 5 illustrates the macro-optical morphologies of the $\mathrm{U}$ and $\mathrm{Al} / \mathrm{U}$ samples after $1.5 \mathrm{~h}$ salt spray corrosion and 1 month sealed reservation. Uranium was heavily corroded with its surface overlaid by an enormous amount of corrosion products, as shown in Fig. $5 a$ and b. From Fig. $5 c$ and d, a few corrosion pits (darker zones) are observed in a randomized arrangement on the surface of the Al film. The diameter of the corrosion pits
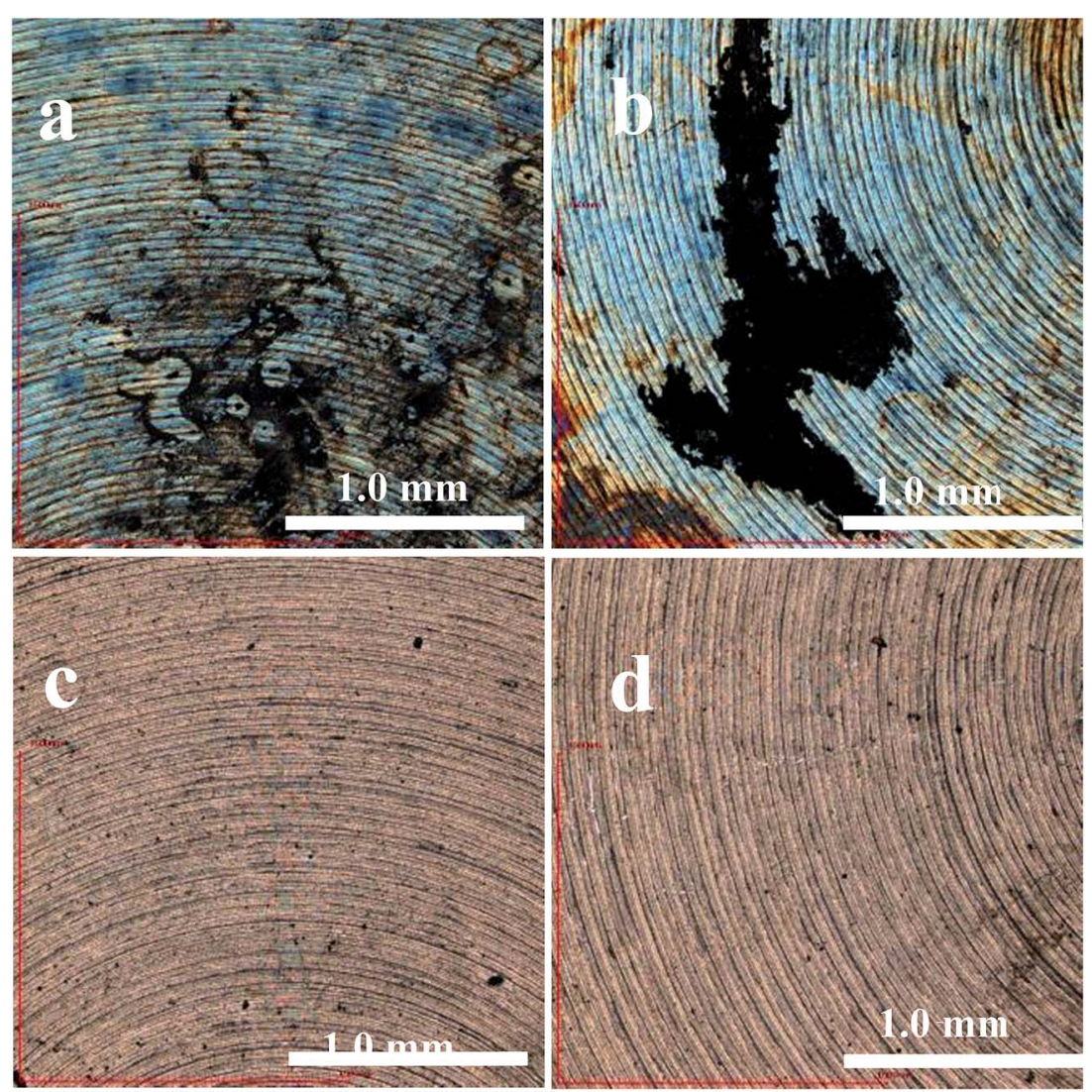

Fig. 3 Macro-optical morphologies of the $U$ ( $a$ and b) and $\mathrm{Al} / \mathrm{U}$ (c and d) samples after $1.5 \mathrm{~h}$ salt spray corrosion. 


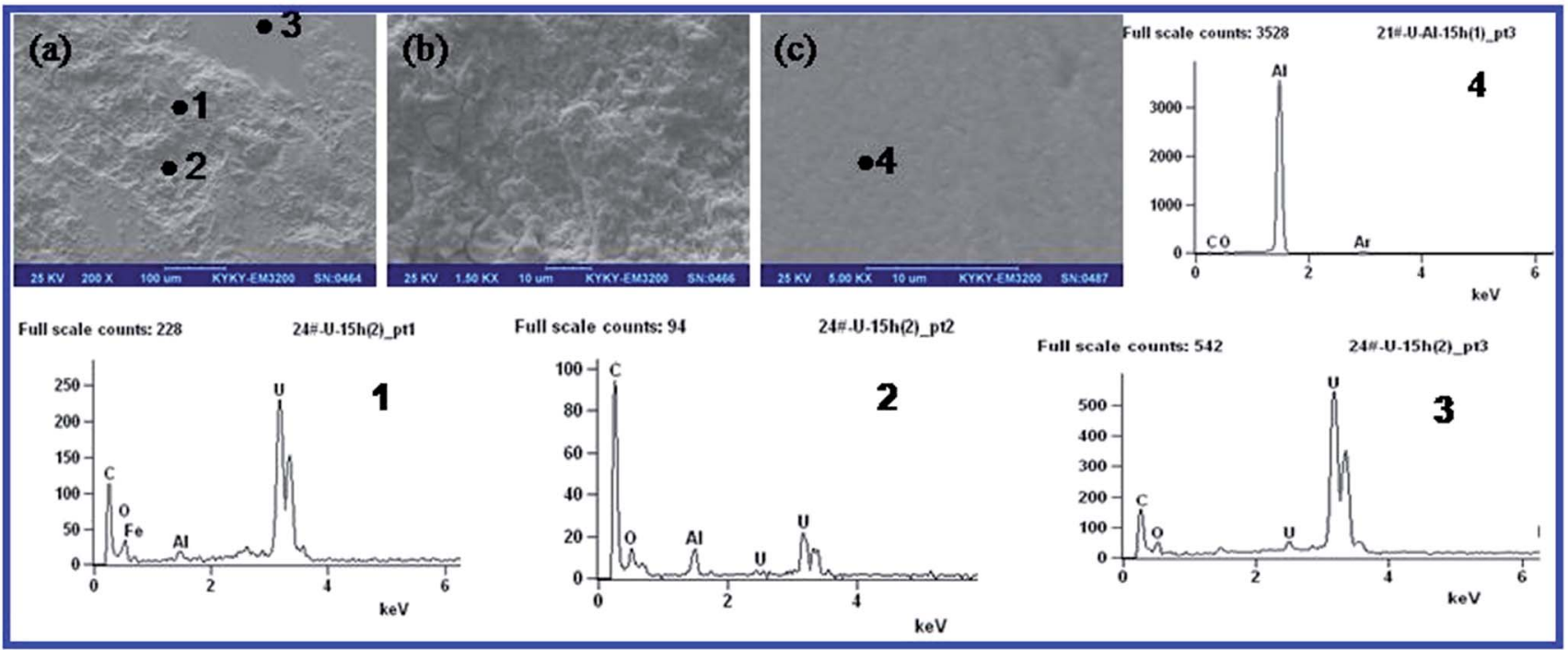

Fig. 4 Micro-structure and EDX spectra of $U(\mathrm{a}$ and $\mathrm{b})$ and $\mathrm{Al} / \mathrm{U}(\mathrm{c})$ after $1.5 \mathrm{~h}$ salt spray corrosion.

is below $50 \mu \mathrm{m}$. The invalidations are mainly expressed in the form of corrosion pits and cracks in uranium (Fig. 5a and b). The corrosion areas connected to each other to form a ring-like morphology along the machining trace. A large amount of debris spalled from the surface, and the largest depth of the corrosion area was about $39.86 \mu \mathrm{m}$.
Fig. 6 shows the micro-structure and EDX spectra of the uranium and Al film after $1.5 \mathrm{~h}$ salt spray corrosion and 1 month sealed reservation. The corrosion areas connected to each other to form a ring-like morphology along the machining trace, as shown in Fig. 6a. Cracks were found on the surface of uranium, as shown in Fig. 6b. From the EDX patterns of spot 1

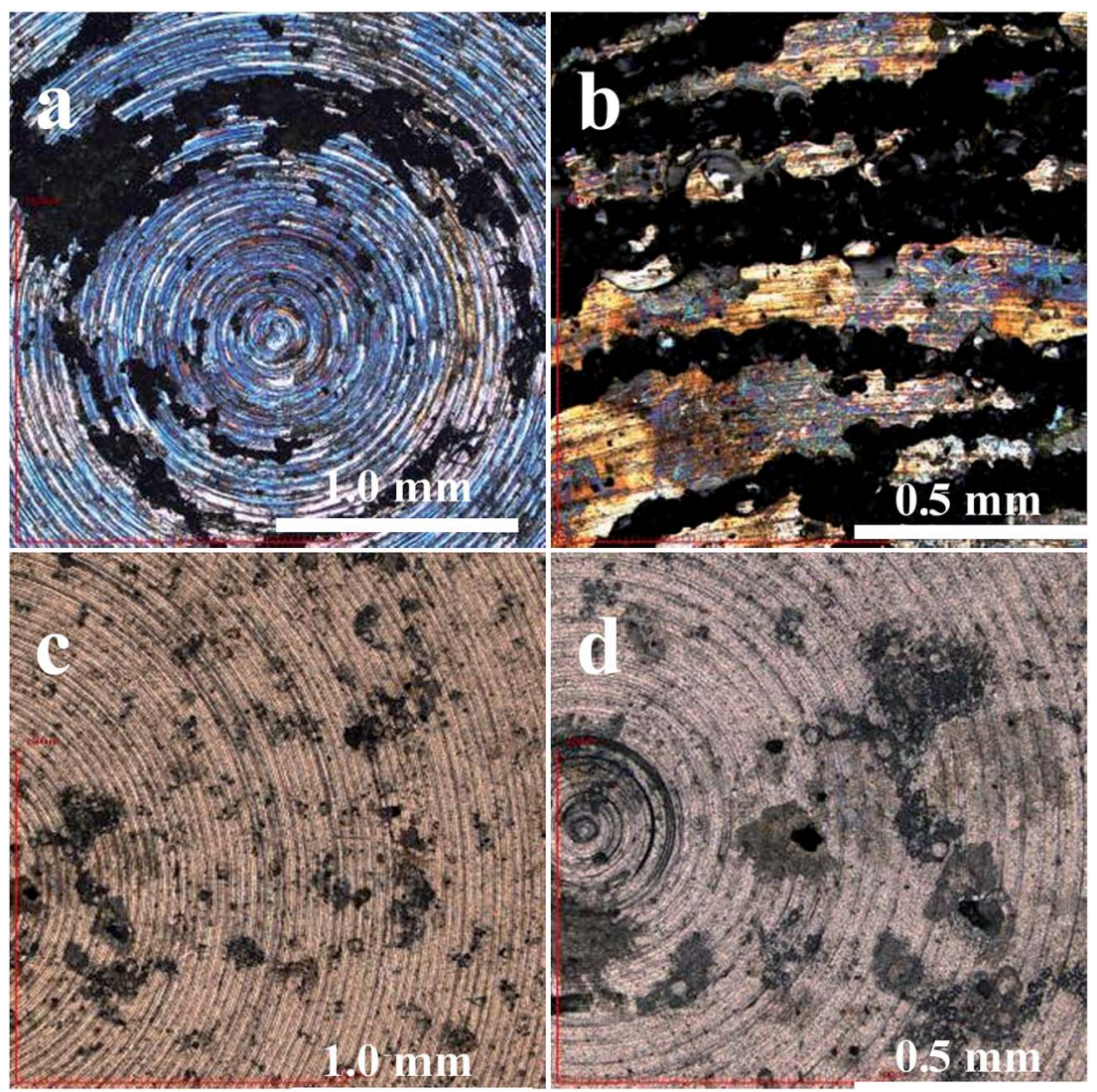

Fig. 5 Macro-optical morphologies of the $U$ ( $a$ and $b$ ) and $\mathrm{Al} / \mathrm{U}$ ( $\mathrm{c}$ and $\mathrm{d}$ ) samples after $1.5 \mathrm{~h}$ salt spray corrosion and $1 \mathrm{month}$ sealed reservation. 


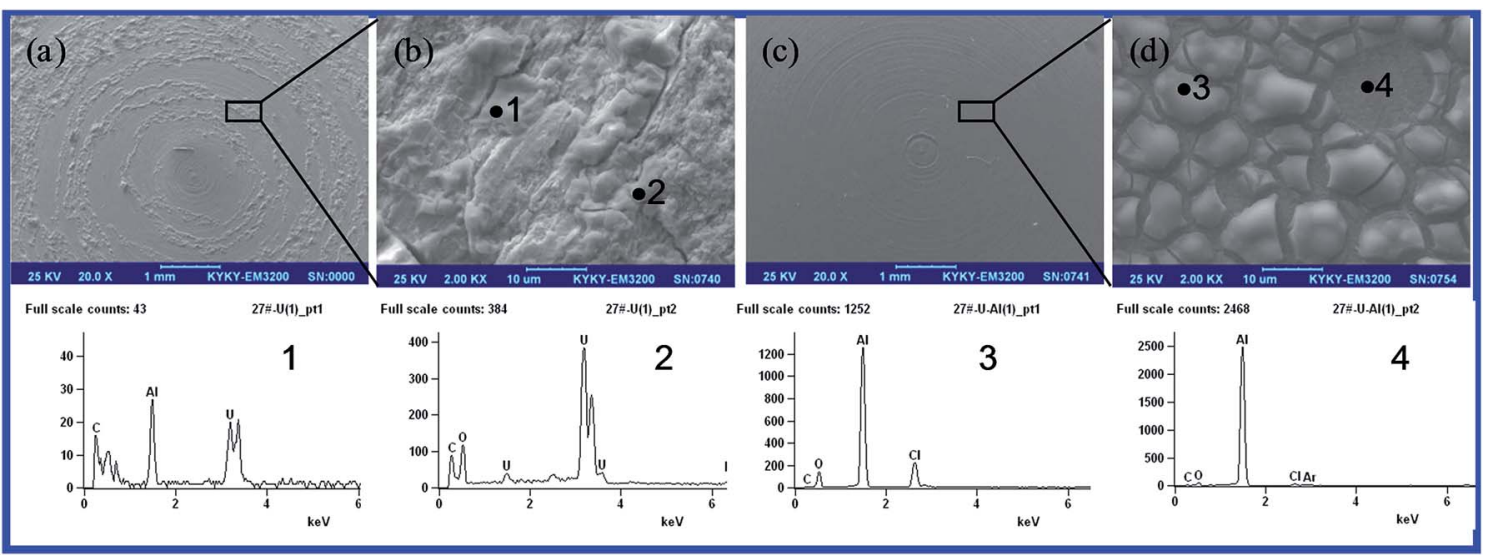

Fig. 6 Micro-structure and EDX spectra of $U$ ( $a$ and $b$ ) and $\mathrm{Al} / \mathrm{U}(\mathrm{c}$ and $\mathrm{d}$ ) after $1.5 \mathrm{~h}$ salt spray corrosion and 1 month sealed reservation.

and spot 2, the elements ( $\mathrm{U}, \mathrm{C}$ and $\mathrm{O}$ ) in the corrosion area are identical. In contrast, the spot 1 corrosion area has a greater content of Al element than the spot 2 area, which means that the area without impurity $\mathrm{Al}$ element was also heavily corroded after 1 month sealed reservation. It can be seen from Fig. 6d that the $\mathrm{Al}$ film chapped after $1.5 \mathrm{~h}$ salt spray corrosion and 1 month sealed reservation. The EDX spectra only show a small amount of $\mathrm{C}, \mathrm{O}, \mathrm{Cl}$ and $\mathrm{Ar}$ elements without the $\mathrm{U}$ element that was obtained in the matrix, which indicate that the Al film was only slightly corroded and uranium was well protected.

\subsection{Potentiodynamic polarization test}

In order to determine the effectiveness of the Al film in corrosion protection, potentiodynamic polarization measurements were conducted in a $50 \mu \mathrm{g} \mathrm{g}^{-1} \mathrm{Cl}^{-}$solution. Fig. 7 shows the potentiodynamic polarization curves of $\mathrm{U}$ and the $\mathrm{Al}$ film on uranium. It can be seen that the samples have the same electrochemical behavior in the test potential range. On the zones
Table 1 Electrochemical corrosion measurement results in $50 \mu \mathrm{g} \mathrm{g}^{-1}$ $\mathrm{Cl}^{-}$solution

\begin{tabular}{llr}
\hline Samples & $E_{\text {corr }}(\mathrm{mV} v s . \mathrm{SCE})$ & $I_{\text {corr }}\left(\mu \mathrm{A} \mathrm{cm}^{-2}\right)$ \\
\hline $\mathrm{U}$ & $-641 \pm 23$ & $2.697 \pm 0.04$ \\
$\mathrm{Al} / \mathrm{U}$ & $-708 \pm 35$ & $0.29 \pm 0.01$
\end{tabular}

above the self-corrosion potentials, the anodic current densities increased rapidly with the enhancement of the polarization potentials. The anodic reaction curve corresponds to the dissolution reactions of uranium and Al. The anodic reaction was inhibited in the presence of the $\mathrm{Al} \mathrm{film,} \mathrm{indicating} \mathrm{that} \mathrm{the}$ Al film effectively enhances the corrosion resistance.

The self-corrosive potential and self-corrosive current is presented in Table 1. Resistance to electrochemical corrosion can be estimated by calculating the sample's self-corrosive potential $\left(E_{\text {corr }}\right)$ and self-corrosive current $\left(I_{\text {corr }}\right)$. A high $E_{\text {corr }}$ indicates good resistance to corrosion, and a low $I_{\text {corr }}$ means

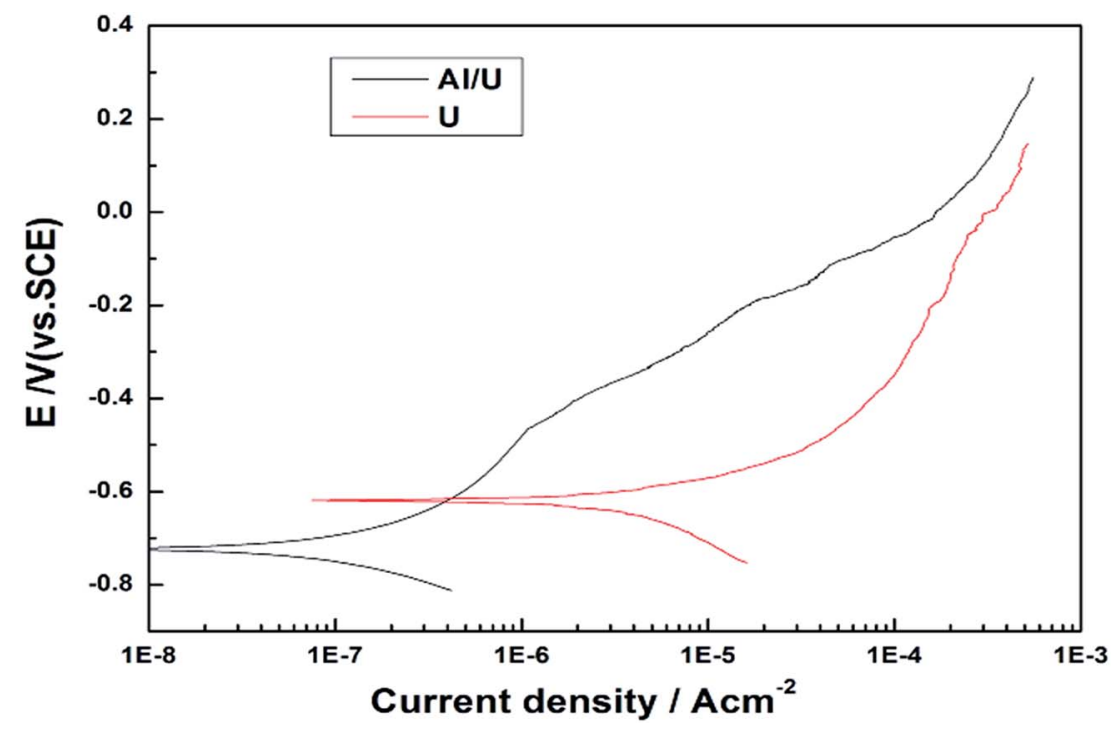

Fig. 7 Polarization curves of $\mathrm{U}$ and $\mathrm{Al} / \mathrm{U}$ in $50 \mu \mathrm{g} \mathrm{g}^{-1} \mathrm{Cl}^{-}$solution. 

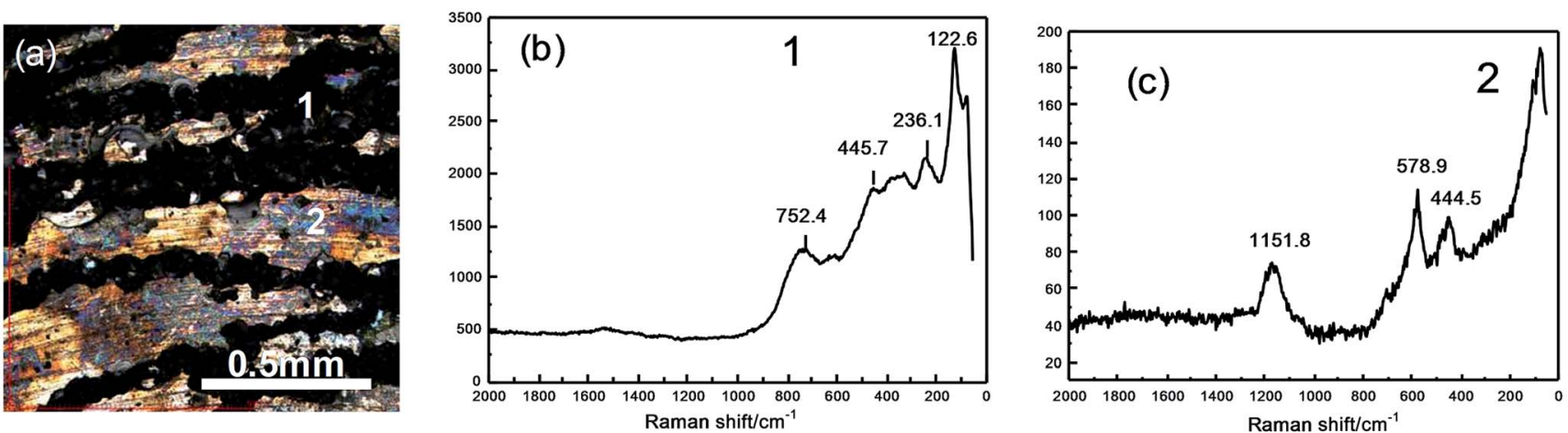

Fig. 8 Optical morphology (a) and Raman spectra of the corrosion product for the severe corrosion region (b) and slight corrosion region (c).

a low corrosion rate. ${ }^{35}$ The self-corrosive potential of uranium is about $-641 \mathrm{mV}$ vs. SCE. The self-corrosive potential of $\mathrm{Al}$ on uranium declined by about $67 \mathrm{mV} v s$. SCE, whereas the corrosion current density dropped by an order of magnitude, indicating lower corrosion rate for the $\mathrm{Al}$ film on uranium. The $\mathrm{Al}$ film possessing a negative electrode potential works as a sacrificial anode, forming a galvanic couple with uranium and is preferentially corroded rather than uranium.

\subsection{Mechanism of salt spray corrosion}

Fig. 8 shows the Raman spectra of the corrosion product of uranium after the salt spray corrosion test. There are four main Raman peaks at the positions of about $112.6 \mathrm{~cm}^{-1}, 236.1 \mathrm{~cm}^{-1}$, $445.7 \mathrm{~cm}^{-1}$ and $752.4 \mathrm{~cm}^{-1}$ (Fig. 8b) at spot 1 (Fig. 8a). There are three main Raman peaks at the positions of about $444.5 \mathrm{~cm}^{-1}$, $578.9 \mathrm{~cm}^{-1}$ and $1151.8 \mathrm{~cm}^{-1}$ (Fig. 8c) at spot 2 (Fig. 8a). The bands at $112.6 \mathrm{~cm}^{-1}, 236.1 \mathrm{~cm}^{-1}$ and $752.4 \mathrm{~cm}^{-1}$ are assigned to $\mathrm{U}_{3} \mathrm{O}_{8}$, and the bands at $444.5 \mathrm{~cm}^{-1}, 578.9 \mathrm{~cm}^{-1}$ and $1151.8 \mathrm{~cm}^{-1}$ are assigned to $\mathrm{UO}_{2} \cdot{ }^{36-38}$ The corrosion product of the darker zones (Fig. 8a) is a mixture of $\mathrm{U}_{3} \mathrm{O}_{8}$ and $\mathrm{UO}_{2}$. The corrosion product of the lighter zones (Fig. $8 \mathrm{a}$ ) is $\mathrm{UO}_{2}$.
An extra thin salt-containing moisture film, with more oxygen adsorbing and dissolving, formed due to deposition during the salt spray test. The salt spray corrosion is electrochemical corrosion. The $\mathrm{Cl}^{-}$in the media accelerated the destruction of the oxidized film and corrosion holes occurred. After the formation of corrosion holes, the dissolution of uranium in the holes accelerated under the effect of a large cathode and small anode. Then, the pits connected to each other, the cracks connected to each other, and finally the layer surface spalling phenomenon appeared.

The typical Auger depth profiles of the $\mathrm{Al}, \mathrm{C}, \mathrm{Cl}$, and $\mathrm{O}$ elements in the $\mathrm{Al}$ film on uranium after salt spray corrosion are illustrated in Fig. 9. On the initial surface, the content of the C and $\mathrm{O}$ elements are very high. With an increase in the $\mathrm{Ar}^{+}$ etching time, the content of $\mathrm{C}$ decreases quickly, which shows that some of the $\mathrm{C}$ element came from the surface contaminants. There is a small content of $\mathrm{Cl}$ at the surface. The content of $\mathrm{O}$ element is very low, and the content of $\mathrm{Al}$ element is over $98 \%$, which indicates that the $\mathrm{Al}$ film is only slightly corroded on the surface and uranium is well protected.

$\mathrm{Al}$ reacts with active oxygen and water, which are formed due to deposition during the salt spray test, to form $\mathrm{Al}(\mathrm{OH})_{3}$ (see eqn

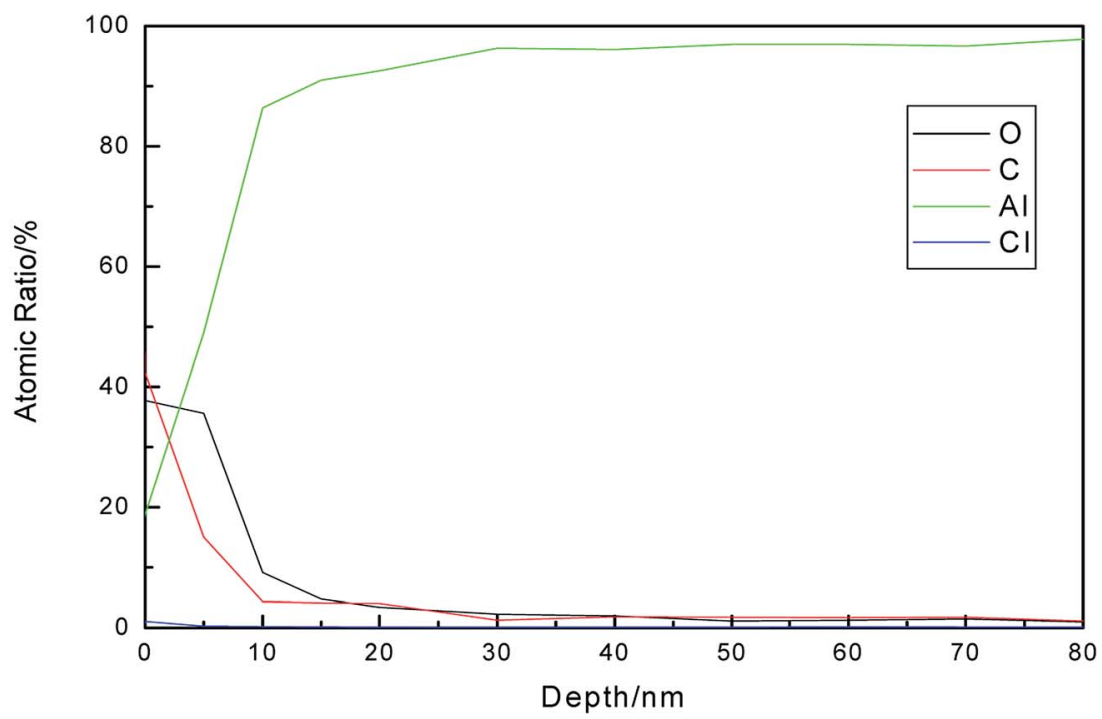

Fig. 9 AES depth profiles of the $\mathrm{Al}, \mathrm{C}, \mathrm{Cl}$ and $\mathrm{O}$ elements in the Al film on uranium after salt spray corrosion. 
(1)). Then, $\mathrm{Cl}^{-}$replaces $\mathrm{OH}^{-} .{ }^{39}$ As can be observed from Fig. 6d and 9, $\mathrm{Cl}$ is found in the EDX and AES results, which indicate that the product is $\mathrm{AlCl}_{3}$ (see eqn (2)).

$$
\begin{gathered}
4 \mathrm{Al}+3 \mathrm{O}_{2}+6 \mathrm{H}_{2} \mathrm{O} \rightarrow 4 \mathrm{Al}(\mathrm{OH})_{3} \\
\mathrm{Al}(\mathrm{OH})_{3}+3 \mathrm{Cl}^{-}+3 \mathrm{H}^{+} \rightarrow \mathrm{AlCl}_{3}+3 \mathrm{H}_{2} \mathrm{O}
\end{gathered}
$$

The surface morphologies of the Al film after salt spray corrosion are illustrated in Fig. 3-6. Only a few corrosion pits are observed on the surface. After 1 month reservation, spalling was found in the $\mathrm{Al}$ film. The main reason for this is that the $\mathrm{Al}$ film had a uniform distribution of elements without a weak zone to cause a large cathode and small anode. The corrosion pits in the $\mathrm{Al}$ film were small and in a randomized arrangement. The Al film was eroded first upon exposure to salt spray as a sacrificial anode to protect uranium.

\section{Conclusion}

An Al film of about $10 \mu \mathrm{m}$ thickness was deposited on depleted uranium using the magnetron sputtering technology to improve its corrosion resistance. There was no columnar crystal structure in the dense Al film. Corrosion pits were found in uranium after exposure to salt spray for $0.5 \mathrm{~h}$ on the area with $\mathrm{Al}$ or $\mathrm{Fe}$ impurity elements. The corrosion areas in the surface of uranium connected to each other to form a ring-like morphology along the machining trace after salt spray exposure for $1.5 \mathrm{~h}$ and sealed reservation for 1 month. The corrosion product was a mixture of $\mathrm{U}_{3} \mathrm{O}_{8}$ and $\mathrm{UO}_{2}$. The Al film was only slightly corroded with a dense layer of corrosion products on the top of the film after $1.5 \mathrm{~h}$ salt spray corrosion. After 1 month reservation, the Al film chapped on the surface. Al film was eroded preferentially upon exposure to salt spray as a sacrificial anode to protect uranium.

\section{Acknowledgements}

We would like to thank Dingmu Lang, Yan Liu and Qingfu Wang for their assistance in experimental measurements. This study is supported by the National Natural Science Foundation of China No. 51401188.

\section{References}

1 C. Alippi, A unique timely moment for embedding intelligence in applications, CAAI Transactions on Intelligence Technology, 2016, 1, 1-3.

2 C. Tang, R. Wang, Z. Li, W. Wang and W. Gao, Frame interpolation with pixel-level motion vector field and mesh based hole filling, CAAI Transactions on Intelligence Technology, 2016, 1, 72-78.

3 D. F. Roeper, D. Chidambaram, C. R. Clayton and G. P. Halada, Development of an Environmental Friendly Protective Coating for the Depleted Uranium-0.75 wt $\%$ Titanium Alloy: Part V. Electrochemical Impedance
Spectroscopy of the Coating, Electrochim. Acta, 2008, 53, 2130-2134.

4 D. F. Roeper, D. Chidambaram, C. R. Clayton and G. P. Halada, Development of an Environmental Friendly Protective Coating for the Depleted Uranium-0.75 wt $\%$ Titanium Alloy: Part I. Surface Morphology and Electrochemistry, Electrochim. Acta, 2005, 50, 3622-3633.

$5 \mathrm{~J}$. M. Haschke, Corrosion of Uranium in Air and Water Vapor: Consequences for Environmental Dispersal, J. Alloys Compd., 1998, 278, 149-160.

6 L. J. Weirick, Hot-dipped Tin-Zinc on U-0. 75 wt\% Ti, SAND79-0478, pp. 1-46.

7 F. Chang, M. Levy, B. Jackman and W. B. Nowak, Assessment of Corrosion-resistant Coatings for a Depleted Uranium-0.75 Titanium Alloy, Surf. Coat. Technol., 1991, 48, 31-39.

8 F. Chang, M. Levy, R. Huie, M. Kane, P. Buckley, T. Z. Kattamis and G. R. Lakshminarayan, Adhesion and Corrosion Behavior of Al-Zn and TiN/Ti/TiN Coatings on a DU-0.75 wt\% Ti Alloy, Surf. Coat. Technol., 1991, 49, 87-96.

9 A. K. Singh, S. Kaity, K. Singh, J. Thomas, T. R. G. Kutty and S. Sinha, Pulsed Laser Deposition of Alumina Coating for Corrosion Protection Against Liquid Uranium, Mater. Chem. Phys., 2014, 143, 1446-1451.

10 T. W. Liu, C. Dong, S. Wu, K. Tang, J. Y. Wang and J. P. Jia, TiN, TiN Gradient and Ti/TiN Multilayer Protective Coatings on Uranium, Surf. Coat. Technol., 2007, 201, 6737-6741.

11 S. Zhu, L. Chen, Y. Wu, Y. Hu, T. Liu, K. Tang and Q. Wei, Microstructure and Corrosion Resistance of $\mathrm{Cr} / \mathrm{Cr}_{2} \mathrm{~N}$ Multilayer Film Deposited on the Surface of Depleted Uranium, Corros. Sci., 2014, 82, 420-425.

12 S. Zhu, Y. Wu, T. Liu, K. Tang and Q. Wei, Interface Structure and Corrosion Resistance of $\mathrm{Ti} / \mathrm{Cr}$ Nanomultilayer Film Prepared by Magnetron Sputtering on Depleted Uranium, ACS Appl. Mater. Interfaces, 2013, 5, 6598-6602.

13 J. Charles and L. J. Weirick, The Oxidation of Uranium-0.75 wt\% Titanium in Environments Containing Oxygen and/or Water Vapor at $140{ }^{\circ} \mathrm{C}, \mathrm{J}$. Nucl. Mater., 1987, 144, 110-120.

14 J. M. Haschke, T. H. Allen and L. A. Morales, Reactions of Plutonium Dioxide with Water and Hydrogen-Oxygen Mixtures: Mechanisms for Corrosion of Uranium and Plutonium, J. Alloys Compd., 2001, 314, 78-91.

15 G. W. McGillivray, D. A. Geeson and R. C. Greenwood, Studies of the Kinetics and Mechanism of the Oxidation of Uranium by Dry and Moist Air: a Model for Determining the Oxidation Rate over a Wide Range of Temperatures and Water Vapor Pressures, J. Nucl. Mater., 1994, 208, 81-97.

16 K. H. Eckelmeyer, A. D. Romig and L. J. Weirick, The Effect of Quench Rate on the Microstructure, Mechanical Properties, and Corrosion Behavior of U-6 Wt Pct Nb, Metall. Mater. Trans. A, 1984, 15, 1319.

17 H. M. Volz, R. E. Hackenberg and A. M. Kelly, X-Ray diffraction analyses of aged U-Nb alloys, J. Alloys Compd., 2007, 444-445, 217-225.

18 Y. Zhang, X. Zhang, X. Cheng, W. Guan and X. Wang, Effect of grain size on phase stability of monoclinic U-Nb alloy during low-temperature aging, J. Nucl. Mater., 2015, 456, 167-169. 
19 V. F. Peretrukhin, A. G. Maslennikov, A. Y. Tsivadze, C. H. Delegard, A. B. Yusov, V. P. Shilov, A. A. Bessonov, K. E. German, A. M. Fedoseev, L. P. Kazanskii, N. Y. Budanova, A. V. Kareta, A. V. Gogolev, K. N. Gedgovd and G. S. Bulatov, Corrosion of uranium and its low content $\mathrm{Zr}, \mathrm{Nb}$, and $\mathrm{Ru}$ alloys in aqueous solution, Prot. Met., 2008, 44, 211-232.

20 B. A. Hilton, Review of oxidation rates of DOE spent nuclear fuel, Part 1: Metallic fuel, Report ANL-00/24, Argonne national laboratory, Idaho Falls, ID, USA, 2000.

$21 \mathrm{~J}$. S. Bullock, Electrochemical studies of uranium alloys corrosion, in Physical Metallurgy of Uranium Alloys, ed. J. J. Burke, Brook Hill, Chestnut Hill, MA, 1976, pp. 847-895.

22 M. Levy and C. V. Zabielski, Physical Metallurgy of Uranium Alloys, ed. J. J. Burke, Hill publishing company, Chestnut Hill, USA, 1976, p. 897.

$23 \mathrm{X}$. Fu, X. Wang, C. Bai and Z. Zhao, Electrochemical corrosion behavior of uranium-niobium alloy in aqueous solutions, Ordnance Mater. Sci. Eng., 2001, 24, 13-16.

24 D. Kelly, J. A. Lillard, W. L. Manner, R. Hanrahan Jr and M. T. Paffett, Surface characterization of oxidative corrosion of U-Nb alloys, J. Vac. Sci. Technol., A, 2001, 19, 1959.

25 S. Orman, Metallurgy of uranium alloys, ed. J. J. Burke and D. A. Colling, J Greenspan Brook Hill, New York, 1974.

26 L. J. Weirick. Corrosion of uranium and uranium alloys, ASM Metals Handbook, American Society of Metals, Metals Park, $\mathrm{OH}, 1988$.

27 F. C. Walsh, C. Ponce, C. Kerr, S. Court and B. D. Barker, Electrochemical characterisation of the porosity and corrosion resistance of electrochemically deposited metal coatings, Surf. Coat. Technol., 2008, 202, 5092-5102.

28 A. Lekatou, D. Zois, A. E. Karantzalis and D. Grimanelis, Electrochemical behavior of cermet coatings with a bond coat on Al7075: Pseudopassivity, localized corrosion and galvanic effect considerations in a saline environment, Corros. Sci., 2010, 52, 2616-2635.
29 J. M. Kochen, The galvanic corrosion behavior of uranium alloys in hydrochloric acid and ocean water, RFP-1592, Rocky Flats Plant, Feb 1971.

$30 \mathrm{~J}$. M. Kochen, The corrosion behavior of uranium-Base $\mathrm{U}-\mathrm{Nb}, \mathrm{U}$ $\mathrm{Nb}-\mathrm{Zr}$, and U-Mo alloys in hydrochloric acid and ocean water, RFP-1586, Rocky Flats Plant, Feb 1971.

31 R. D. Bland, Ion-plated coating for the corrosion protection of uranium, Atomic energy commission contract report, 1965, SC-DR-65-519.

32 Z. Pu, Q. Wang and M. Shuai, Galvanic corrosion between depleted uranium and 40Cr steel, Int. J. Electrochem. Sci., 2013, 8, 991-1001.

33 Z. Pu, Q. Wang and M. Shuai, Galvanic corrosion between depleted uranium and 45 steel, Mater. Sci. Forum, 2013, 749, 606-610.

34 J. Zhu, S. Wei, I. Y. Lee, S. Park, J. Willis, N. Haldolaarachchige, D. P. Young, Z. Luo and Z. Guo, Silica stabilized iron particles toward anti-corrosion magnetic polyurethane nanocomposites, RSC Adv., 2012, 2, 1136-1143.

35 Z. B. Bao, Q. M. Wang, W. Z. Li, J. Gong, T. Y. Xiong and C. Sun, Corrosion behavior of AIP NiCoCrAlYSiB coating in salt spray tests, Corros. Sci., 2008, 50, 847-855.

36 M. L. Palacios and S. H. Taylor, Characterization of uranium oxides using in situ micro-Raman spectroscopy, Appl. Spectrosc., 2000, 54(9), 1372-1378.

37 D. Manara and B. Renker, Raman spectra of stoichiometric and Hyperstoichiometric uranium dioxide, J. Nucl. Mater., 2003, 321(2-3), 233-237.

38 E. A. Stefaniak, A. Anita and W. Anna, Recognition of uranium oxides in soil particulate matter by means of $\mu$ Raman spectrometry, J. Nucl. Mater., 2008, 381(15), 278-283.

39 C. F. Dong, Y. H. An, X. G. Li, H. Sheng and K. Xiao, Electrochemical performance of initial corrosion of 7A04 aluminium alloy in marine atmosphere, Chin. J. of Nonferrous Met., 2009, 19, 346-352. 